\title{
A Review of Language Learning Strategy Research
}

\author{
Yanfei Su \\ Sichuan University of Arts and Science, Dazhou, China
}

\begin{abstract}
Language learning strategy, a crucial variable of individual differences in second language acquisition (SLA), has been a fiercely discussed topic since 1970s, attracting a large number of researchers and teachers who have already made great achievements. This article aims to conduct a small-scale review of studies concerning language learning strategy, finding that studies in this respect were done mainly from perspectives of definition, identification and classification, usage and assessment and instruction of language learning strategy, and factors which exert influences on it. It is plausible to say that research on this issue is comparatively comprehensive, appreciating wide coverage and great achievements, but certain points are still in controversy. Although there are many related studies, rare studies were devoted to language learning strategy under the context of learners in mainland China. Subsequently, implications for further research and pedagogy in terms of language learning strategy are discussed.
\end{abstract}

Index Terms - language learning strategy, definition, identification and classification, usage and assessment, instruction, factor

\section{INTRODUCTION}

Since the career of English teacher has begun, a phenomenon have been noticed that students in a same class taught by a same teacher using same teaching methods perform differently in English acquisition, with some students being more successful than others, no matter English as a mother language, second language or foreign language. It is consistent with what Gass \& Selinker (2008) pointed out that "one of the most widely recognized facts about second language learning is that some individuals are more successful in learning a second language than other individuals" (p. 395). Of course, there is a series of complicated factors behind the phenomenon, which interact with each other to exert influence on students' second/foreign language learning. Some are extrinsic, being related to language and society, while some are intrinsic, being related to students themselves, for instance, aptitude, motivation, attitude, gender, learning style, language proficiency, autonomy and the like (Carson \& Longhini, 2002; Gass \& Selinker 2008; Murray, 2010; Nisbet, Tindall \& Arroyo, 2005; Park, 1997; Wharton, 2000). This article conducts a review of studies revolving around one of those variables in individual differences in second/foreign language acquisition, that is, language learning strategy.

Taking language learning strategy as the core, libraries were visited and the Internet was surfed so as to find as more studies concerning this issue as possible, then using language learning strategy (ies) as key words to search relevant studies in order to find lots of studies in this respect as well and finally choosing those whose titles have key words of (language) learning strategy (ies). After such kind of literature retrieval, 24 journal articles and books were gathered, which were used as the subject of analysis in this paper. After reviewing and analyzing these studies, this article summarizes different perspectives of language learning strategy research and discusses their implications for further research and pedagogy.

\section{LITERATURE REVIEW}

Since 1970s, growing studies have focused their attention on language learning strategy, which could be generally divided into two broad areas, that is, theoretical research and empirical research. After conducting a small-scale review of studies about language learning strategy which were retrieved, different perspectives of language learning strategy research could be discerned, namely, definition, identification and classification, practical usage and assessment, and training/instruction of language learning strategy, and factors influencing language learning strategy use.

In fact, those studies cannot be divided in such a clear-cut way because a number of studies are involved in more than one aspect. For instance, O'Malley \& Chamot (1990) investigated language learning strategy systematically by reviewing previous research, explaining rationale for and contribution to integrating cognitive theory into strategy research, and discussing its definition, classification, usage, effectiveness, and instruction. Similarly, Oxford (1990) conducted a comparatively complete research, including its definition, feature, classification, assessment and instruction, and how to apply strategies to listening, speaking, reading, and writing. Torres (2013) reviewed certain definitions and classifications of language learning strategy, examined "good" language learners' strategy use and proposed an approach to strategy training and self-regulatory awareness practice. While there are some scholars who conducted a literature review, discussing strategy training model, definition, classification, and factors influencing language learning 
strategy use (Lee, 2010; Liu, 2010). This article makes a classification of the retrieved studies in such a way in order to gain a general scenery of studies about language learning strategy. The classification is as follows.

Firstly, in terms of the definition of language learning strategy, it has not been reached a consensus. There are different descriptions of definition of language learning strategy. Scholars have discussed it from different angles (Cohen, 1998; Lee, 2010; Liu, 2010; O’Malley \& Chamot, 1990; Oxford, 1990; Scarcella \& Oxford, 1992; Torres, 2013; Tseng, Dörnyei \& Schmitt, 2006). Oxford gave a definition of language learning strategy as "specific actions taken by the learner to make learning easier, faster, more enjoyable, more self-directed, more effective, and more transferrable to new situations" (Oxford, 1990, p. 8). On the other hand, Scarcella and Oxford defined it as "specific actions, behaviors, steps, techniques [or thoughts] — such as seeking out conversation partners, or giving oneself encouragement to tackle a difficult language task - used by students to enhance their own learning" (Oxford, 2003, p. 274). Cohen believed that language learning strategies are "those processes which are consciously selected by learners and which may result in action taken to enhance the learning or use of a second or foreign language, through the storage, retention, recall, and application of information about that language" (Gass \& Selinker, 2008, p. 439). O'Malley \& Chamot thought learning strategies as "the special thoughts or behaviors that individuals use to help them comprehend, learn, or retain new information" (O’Malley \& Chamot, 1990, p. 1).

Although the wording of definitions of language learning strategy proposed by different scholars varies, there are some common points behind them, which are of great importance. Oxford summarized those common points of language learning strategy as follows:

1. Contribute to the main goal, communicative competence.

2. Allow learners to become more self-directed.

3. Expand the role of teachers.

4. Are problem-oriented.

5. Are specific actions taken by the learner.

6. Involve many aspects of the learner, not just the cognitive.

7. Support learning both directly and indirectly.

8. Are not always observable.

9. Are often conscious.

10. Can be taught.

11. Are flexible.

12. Are influenced by a variety of factors (Oxford, 1990, p. 9).

Secondly, some researchers were committed to identifying and classifying different types of language learning strategies (O’Malley \& Chamot, 1990; Oxford, 1990; Rubin, 1981). There are many ways to identify language learning strategies such as interviews, diaries, questionnaires, and think aloud protocol. The think aloud protocol might be the most popular way to identify language learning strategies. After identifying different strategies, scholars embarked on classifying them and different scholars have different classification modes. O'Malley \& Chamot (1990) classified language learning strategies into three broad types, that is, metacognitive strategies, cognitive strategies, and social/affective strategies (pp. 42-55). Oxford divided the language learning strategies into "two major classes: direct and indirect. These two classes are subdivided into a total of six groups (memory, cognitive, and compensation under the direct class; metacognitive, affective, and social under the indirect class)" (Oxford, 1990, p.14). Rubin classified them into strategies that directly affect learning, including clarification/verification, monitoring, memorisation, guessing/inductive inferencing, deductive reasoning, and practice, and processes that contribute indirectly to learning, including creation of opportunities for practice and production tricks (Lee, 2010, p139).

Thirdly, how learners use language learning strategies and how to assess the usage of language learning strategies attracted attentions of other researchers and teachers (Fan, 2003; Gu, Hu \& Zhang, 2005; Lai, 2009; Murray, 2010; Park, 1997; Vandergrift, 2003; Wharton, 2000). Gu, Hu \& Zhang (2005) conducted an empirical study on lower primary school pupils' use of language learning strategies in Singapore to check whether the think-aloud protocol would be applicable to investigate children's language learning strategy use. Wharton (2000) studied strategy use by university students learning Japanese and French as foreign languages in Singapore and factors impacting their strategy use based on Oxford's (1990) SILL. Vandergrift (2003) examined listening strategy use by grade 7 students learning French as a foreign language, finding that more skilled and less skilled listeners used strategies differently. Lai (2009) researched strategy use by EFL learners in Taiwan with result that proficient and less proficient subjects adopted different strategies. Fan (2003) studied Cantonese speakers learning English vocabulary, focusing on identification of vocabulary learning strategies.

In order to assess the effectiveness of a certain language learning strategy use, a majority of scholars adopted Oxford's SILL (Carson \& Longhini, 2002; Hsiao \& Oxford, 2002; Lee, 2010; Murray, 2010; Nisbet, Tindall \& Arroyo, 2005; Park, 1997; Wharton, 2000). Meanwhile, realizing certain limitations of SILL, some scholars gave thought about new approaches to assess language learning strategy use (Tseng, Dörnyei \& Schmitt, 2006). Tseng, Dörnyei \& Schmitt (2006) proposed "Self-Regulating Capacity in Vocabulary Learning" (SRCvoc) to measure language learners' selfregulatory capacity in English vocabulary learning. Setiyadi (2014) investigated language learning strategies employed by $88 \mathrm{EFL}$ students at an Indonesian university and then put forward a language learning strategy measurement for EFL 
learners. Woodrow (2005) discussed usefulness of using Likert-type scales to assess learning language strategies, finding it was not appropriate and proposed a new approach using qualitative methods.

Fourthly, different learners have the possibility of using different strategies successfully or unsuccessful because there are factors of variety behind it which influence learning language strategy use. Adopting a diary study, Carson \& Longhini (2002) investigated the learning environment (Spanish-speaking Argentina) and learning style influencing the diarist's strategy use by employing Oxford's SILL. Murray (2010) examined the factor of language proficiency in context of Korean as a foreign language by utilizing Oxford's SILL with result that a generally low positive relation between strategy use and proficiency was found. Utilizing Oxford's SILL, Park (1997) conducted research on EFL university students in Korea, focusing on the factor of language proficiency with results that there is a linear relation between them and certain strategies are used more frequently than others. Nisbet, Tindall \& Arroyo (2005) adopted Oxford's SILL to examine factors of language proficiency and gender in the context of Chinese EFL university students with results that minimal correlation between proficiency and strategy use was found, and it seemed gender didn't exert influence on language learning strategy use. Wharton discussed factors affecting strategy use by university students learning Japanese and French in Singapore, language proficiency and gender in particular, while at the same time listing a series of factors as follows:

A number of factors are assumed to affect the types, numbers, and frequency of use of language learning strategies: cultural background, language studied, stage of learning, age, motivation, language learning goals, FL versus second language (SL) settings, previous language learning experience, language learning styles (including the influence of language teaching methods and task requirements), gender, anxiety, lack of inhibition, and career or academic specialization (Wharton, 2000, p. 207).

Fifthly, some researchers and teachers have invested great efforts in studying instruction/training of language learning strategies. Although there is a minority of scholars who believe there is little or no relation between language learning strategy use and development of language learning, a number of studies show that successful language learners could appropriately utilize various strategies with a high frequency in different contexts, while less successful language learners usually use fewer strategies in a less efficient way. Generally speaking, language learning strategies could be helpful to improve learners' language learning. "L2 learning strategies can help learners improve their own perception, reception, storage, retention, and retrieval of language information" (Oxford, 2003, p. 274). Oxford (1990) believed appropriate language learning strategies could improve learners' proficiency and self-confidence (p. 1). And Lai (2009) thought "training students in using learning strategies and assisting them in developing their own unique ways of learning would make them independent and effective learners" (p. 276). Moreover, "less successful language learners can be taught new strategies, thus helping them become better language learners" (Chamot, 2005, p. 112). "In general, strategy specialists believe that learners with strategic knowledge of language learning, compared with those without, become more efficient, resourceful, and flexible, thus acquiring a language more easily" (Tseng, Dörnyei \& Schmitt, 2006, p. 78).

Since language learning strategy use is proved to be useful and beneficial to language learning in most cases, whether language learning strategies from successful learners could be taught to or shared with those less successful ones, or in other words, is language learning strategy teachable? As for this question, scholars hold different viewpoints. On the one hand, a minority of scholars hold negative viewpoints (Plonsky, 2011; Rees-Miller, 1993; Skehan, 1989). "Studies of SI [strategy instruction] have also produced negative and mixed results across many of the same contexts, treatments, and outcome variables" (Plonsky, 2011, p. 994). "Although most researchers of language learning strategies believe learning strategies can be taught, others (Rees-Miller, 1993; Skehan, 1989) are more skeptical or cautious" (Wharton, 2000, p. 206). On the other hand, a majority of scholars cherish positive views (Hassan, et al, 2005; Macaro, 2006; Park, 1997;). Park (1997) suggested that language learning strategies should be taught in class. "Despite some setbacks and some reservations, learner strategy instruction (or 'training') appears to be effective in promoting successful learning if it is carried out over lengthy periods of time and if it includes a focus on meta-cognition" (Macaro, 2006, p. 321). Hassan, Macaro, Mason, Nye, Smith \& Vanderplank (2005) conducted a deep review of 38 studies concerning language learning strategy training, pointing out "there is sufficient research evidence to support claims that training language learners to use strategies is effective, but it is not possible to say from this evidence whether the effect of training is long-lasting or not" (Hassan, et al., 2005).

It seems that people holding positive view about effectiveness of language learning strategy instruction/training outnumber those holding negative view. At all events, it is advisable that teachers should grasp a deep understanding of language learning strategies so that they can help students adopt appropriate strategies to aid their language learning. This article aims to embark on this issue by conducting a literature review of language learning strategies as the first step, hoping teachers/instructors who haven't given a thought on this point now gain a primary understanding of it.

\section{DISCUSSION AND IMPLICATION}

As far as language learning strategy research is concerned, it has a comparatively comprehensive coverage varying from definition, identification, classification, usage, assessment, instruction to factors influencing language learning strategy. Nonetheless, some research perspectives might deserve in-depth study. 
First of all, great attention were paid to relationship between language proficiency and learning strategy use, whereas certain factors such as culture, learning environment, learning style and so on get little attention. Therefore, relevant studies could expand their coverage to new factors.

Secondly, a large number of previous studies utilized the classification system of Oxford's SILL (Strategy Inventory for Language Learning) while investigating language learning strategy use. The SILL which has two versions, namely, Version 5.1 and Version 7.0, is a structured survey based on Oxford's (1990) strategy system. It consists of multiplechoice questions and is graded by the 5-point scale ranging from "never or almost never" to "always or almost always" to assess frequency of language learning strategy use. Version 5.1 containing 80 items is aimed at native English speakers, while Version 7.0 having 50 items is targeted against learners of English as a second or foreign language (Oxford, 1990, p. 199). Oxford's SILL has been questioned by some scholars. For instance, Tseng, Dörnyei \& Schmitt (2006) pointed out, "the scales in the SILL are not cumulative and computing mean scale scores is not justifiable psychometrically" (p. 83). Therefore, it is advised that future research could conduct experiments about different classification systems or put forward new systems.

Thirdly, it is of great possibility that a number of teachers do not grasp a large repertoire of language learning strategies (in fact, many teachers haven't given a thought on language learning strategies, but they just teach what the course books tells), or they know many language learning strategies, but they just don't know how to explicitly instruct/train students in this respect; on the contrary, there is also another possibility that some researchers grasp a large repertoire of language learning strategies, but they do not have opportunities to apply them to classrooms or they don't have opportunities to share with teachers. Therefore, it is advisable that researchers and teachers would work together to run training workshops or programs for training pre-service and in-service teachers, especially for those at ordinary universities (contrast to those prestigious universities) who had rare opportunities to take further education in this regard. Or forums or conferences concerning such kind of topics could be held frequently to facilitate communications in this field between researchers and teachers.

Fourthly, which language learning strategies could be taught or how to conduct strategies instruction deserves researchers and teachers' attention because language teachers could take full advantages of first-hand materials directly to help students acquire a certain language and an effective language learning strategy would be much helpful to language learners. Moreover, corresponding materials and curriculum development revolving around language learning strategies should be worthy of investing great efforts. And more action studies would be designed to test the effectiveness of a certain language learning strategies.

Last but not least, with the deepening of China's Reform and Opening-up and the Belt and Road Initiative, growing Chinese begin to actively learn English as a foreign language, covering every levels of education in China from kindergarten to doctor; however, it is not hard to find that rare studies have been devoted to language learning strategy use in context of Chinese university students, let alone those at tier-3 university (universities in China could be generally divided into three types hierarchically, namely, top universities as tier-1, major universities as tier-2, and ordinary universities as tier-3). Consequently, attentions might be paid more to Chinese university students who are learning English language, in particular those tier-3 university students and primary or secondary school students in order to help them improve their English learning.

On the other hand, language learning strategy instruction deserves attention as well. Although there are many studies focusing on strategy instruction, it still needs more efforts to study how to conduct strategy instruction and how to instruct teachers to instruct language learning strategy to facilitate language learners acquire a certain language. Just as Plonsky pointed out that "turning to the effects of SI [strategy instruction] with different outcome variable, the data indicate that SI is much more effective for certain skills than for others" (Plonsky, 2011, p. 1010), teachers should take different factors into consideration and then decide which strategies should be adopted to be explicitly taught. Furthermore, teachers could choose certain strategies which they think are appropriate to design certain action research projects in order to check whether they are indeed helpful to their students under that context. Then, teachers should make a clear explanation for students that "a learning strategy cannot, a priori, be categorized as either good or bad" (Oxford, 2003, p. 274), but be appropriate for certain people in certain context. Next, researchers or language teachers from different countries or in different contexts of language learning would be encouraged to share their first-hand studies or experiences so as to cover a wider area of language learning strategies. Moreover, the subjects of studies in terms of language learning strategies would be expanded and be covered more to middle schools because a successful language experience should be based on a solid language base, consequently, it is of necessity to conduct more studies about language learning strategies of primary and secondary students in order to help them grasp a more effective language learning strategies to improve their language proficiency.

\section{CONCLUSION}

Language learning strategies, as an important variable of individual differences of second language acquisition, play a crucial role in language learning and attract lots of attention from researchers and teachers. Numerous studies were devoted to language learning strategies, covering a wide area. This article conducts a small-scale review of studies concerning language learning strategies and generally divides them into several perspectives of definition, identification and classification, usage and assessment, and instruction/training of language learning strategies, and factors 
influencing language learning strategy use. Although research on this issue covers comparatively complete perspectives, some perspectives still need in-depth research theoretically and pedagogically. For example, factors like culture, learning settings, styles and others impacting strategy use deserve further research. New classification systems of language learning strategies should be proposed under the backdrop of changing learning environments and methods to advance with the times. Materials and curriculum about language learning strategy instruction should be developed correspondingly. Training workshops for teachers in terms of strategy instruction should be run. More forums or conferences in this field would be held to facilitate communication between researchers and teachers. Then the language learning strategy research of English as a foreign language in the context of China's education deserve more attention.

\section{ACKNOWLEDGMENTS}

This work is supported in part by a grant from "2017-2019 Education Research and Reform Project of Sichuan University of Arts and Science (2017JY15)".

\section{REFERENCES}

[1] Carson, J.G., \& Longhini, A. (2002). Focusing on learning styles and strategies: a diary study in an immersion setting. Language Learning, 52 (2), 401-438.

[2] Chamot, A. U. (2005). Language learning strategy instruction: current issues and research. Annual Review of Applied Linguistics, 25, 112-130.

[3] Fan, M.Y. (2003). Frequency of use, perceived usefulness, and actual usefulness of second language vocabulary strategies: a study of Hong Kong learners. The Modern Language Journal, 87, 222-241.

[4] Gass, S. M., \& Selinker, L. (2008). Second language acquisition: an introductory course (3rd ed). New York: Routledge.

[5] Gu, P.Y., Hu, G.W., \& Zhang, L.J. (2005). Investigating language learner strategies among lower primary school pupils in Singapore. Language and Education, 19 (4), 281-303.

[6] Hassan, X., Macaro, E., Mason, D., Nye, G., Smith, P., \& Vanderplank, P. (2005). Strategy training in language learning: a systematic review of available research. In: Research Evidence in Education Library. London: EPPI-Centre, Social Science Research Unit, Institute of Education, University of London. Retrieved from: http://eppi.ioe.ac.uk/cms/Default.aspx?tabid=297 (2014.11.16).

[7] Hsiao, T.Y. \& Oxford, R.L. (2002). Comparing theories of language learning strategies: a confirmatory factor analysis. The Modern Language Journal, 86, 368-383.

[8] Lai, Y.C. (2009). Language learning strategy use and English proficiency of university freshmen in Taiwan. TESOL Quarterly, $43(2), 255-280$.

[9] Lee, C.K. (2010). An overview of language learning strategies. ARECLS, 7, 132-152.

[10] Liu, J. (2010). Language learning strategies and its training model. International Education Studies, 3 (3), 100-104.

[11] Macaro, E. (2006). Strategies for language learning and for language use: revising the theoretical framework. The Modern Language Journal, 90, 320-337.

[12] Murray, B. (2010). Students' language learning strategy use and achievement in the Korean as a foreign language classroom. Foreign Language Annals, 43 (4), 624-634.

[13] Nisbet, D.L., Tindall, E.R., \& Arroyo, A.A. (2005). Language learning strategies and English proficiency of Chinese university students. Foreign Language Annals, 38 (1), 100-107.

[14] O’Malley, J.M., \& Chamot, A.U. (1990). Learning Strategies in Second Language Acquisition. Cambridge: Cambridge University Press.

[15] Oxford, R.L. (1990). Language Learning Strategies: What Every Teacher Should Know. Boston: Heinle \& Heinle Publishers.

[16] Oxford, R.L. (2003). Language learning styles and strategies: concepts and relationships. International Review of Applied Linguistics in Language Teaching, 41 (4), 271-278.

[17] Park, G.P. (1997). Language learning strategies and English proficiency in Korean university students. Foreign Language Annals, 30 (2), 211-221.

[18] Plonsky, L. (2011). The effectiveness of second language strategy instruction: a meta-analysis. Language Learning, 61 (4), 993-1038.

[19] Setiyadi, A.B. (2014). Skill-based categories: an alternative of language learning strategy measurement. Journal of Language Teaching and Research, 5 (2), 360-370.

[20] Torres, G. (2013). Empowering the language learner: language learning strategy training and self-regulation in an EFL classroom. Journal of International Education Research, 9 (3), 267-276.

[21] Tseng, W.T., Dörnyei, Z. \& Schmitt, N. (2006). A new approach to assessing strategic learning: the case of self-regulation in vocabulary acquisition. Applied Linguistics, 27(1), 78-102.

[22] Vandergrift, L. (2003). Orchestrating strategy use: toward a model of the skilled second language listener. Language Learning, 53 (3), 463-496.

[23] Wharton, G. (2000). Language learning strategy use of bilingual foreign language learners in Singapore. Language Learning, 50 (2), 203-243.

[24] Woodrow, L. (2005). The challenge of measuring language learning strategies. Foreign Language Annals, 38 (1), 90-98.

Yanfei Su was born in Meishan City, Sichuan Province, China in 1986. She received her Master's Degree in Foreign Language and Literature from Sichuan International Studies University, China in 2010. 
She is currently a lecturer in the School of Foreign Languages, Sichuan University of Arts and Science, Sichuan, China. Her research interests include translation teaching and English language teaching. 